\title{
Integrated Risk Management in Supply Chains
}


Other titles in Foundations and Trends ${ }^{\circledR}$ in Technology, Information and Operations Management

Designing Effective Supply Chains in Strategic Alignment with Demand Characteristics and Market Requirements

Mojtaba Mahdavi and Tava Lennon Olsen

ISBN: 978-1-68083-268-6

Last-mile Supply Network Distribution in Omnichannel Retailing: A Configuration-Based Typology

Stanley Frederick W. T. Lim, Elliot Rabinovich, Dale S. Rogers, and Timothy M. Laseter

ISBN: 978-1-68083-184-9

Performance Improvement in Health Care Organizations Hummy Song and Anita Tucker

ISBN: 978-1-68083-192-4

Integrated Modeling for Location Analysis

Ho-Yin Mak and Zuo-Jun Max Shen

ISBN: 978-1-68083-190-0 


\title{
Integrated Risk Management in Supply Chains
}

\author{
Edited by \\ Panos Kouvelis \\ Olin Business School \\ Washington University in St. Louis, USA \\ kouvelis@wustl.edu \\ Ling Dong \\ Olin Business School \\ Washington University in St. Louis, USA \\ dong@wustl.edu \\ Danko Turcic \\ Olin Business School \\ Washington University in St. Louis, USA \\ turcic@wustl.edu
}




\title{
Foundations and Trends $^{\circledR}$ in Technology, Informa- tion and Operations Management
}

\author{
Published, sold and distributed by: \\ now Publishers Inc. \\ PO Box 1024 \\ Hanover, MA 02339 \\ United States \\ Tel. +1-781-985-4510 \\ www.nowpublishers.com \\ sales@nowpublishers.com \\ Outside North America: \\ now Publishers Inc. \\ PO Box 179 \\ 2600 AD Delft \\ The Netherlands \\ Tel. +31-6-51115274
}

The content of the book was originally published in Foundations and Trends ${ }^{\circledR}$ in Technology, Information and Operations Management, vol. 11, nos. 1-2.

ISBN: 978-1-68083-379-9

(C) 2017 Now Publishers Inc

\begin{abstract}
All rights reserved. No part of this publication may be reproduced, stored in a retrieval system, or transmitted in any form or by any means, mechanical, photocopying, recording or otherwise, without prior written permission of the publishers.

Photocopying. In the USA: This journal is registered at the Copyright Clearance Center, Inc., 222 Rosewood Drive, Danvers, MA 01923. Authorization to photocopy items for internal or personal use, or the internal or personal use of specific clients, is granted by now Publishers Inc for users registered with the Copyright Clearance Center (CCC). The 'services' for users can be found on the internet at: www.copyright.com

For those organizations that have been granted a photocopy license, a separate system of payment has been arranged. Authorization does not extend to other kinds of copying, such as that for general distribution, for advertising or promotional purposes, for creating new collective works, or for resale. In the rest of the world: Permission to photocopy must be obtained from the copyright owner. Please apply to now Publishers Inc., PO Box 1024, Hanover, MA 02339, USA; Tel. +1 781871 0245; www.nowpublishers.com; sales@nowpublishers.com

now Publishers Inc. has an exclusive license to publish this material worldwide. Permission to use this content must be obtained from the copyright license holder. Please apply to now Publishers, PO Box 179, 2600 AD Delft, The Netherlands, www.nowpublishers.com; e-mail: sales@nowpublishers.com
\end{abstract}




\title{
Foundations and Trends ${ }^{\circledR}$ in Technology, Information and Operations Management \\ Volume 11, Issue 1-2, 2017 \\ Editorial Board
}

\author{
Editor-in-Chief \\ Charles Corbett \\ UCLA, Anderson School of Management \\ United States
}

\section{Editors}

Fernando Bernstein

Duke University

Cheryl Gaimon

Georgia Institute of Technology

Uday Karmarkar

University of California, Los Angeles

Sunder Kekre

Carnegie Mellon University

Panos Kouvelis

Washington University

Michael Lapré

Vanderbilt University

Karl Ulrich

University of Pennsylvania

Luk van Wassenhove

INSEAD 


\section{Editorial Scope}

\section{Topics}

Foundations and Trends ${ }^{\circledR}$ in Technology, Information and Operations Management publishes survey and tutorial articles in the following topics:

- B2B Commerce

- Business Process Engineering and Design

- Business Process Outsourcing

- Capacity Planning

- Competitive Operations

- Contracting in Supply Chains

- E-Commerce and E-Business Models

- Electronic markets, auctions and exchanges

- Enterprise Management Systems

- Facility Location

- Information Chain Structure and Competition

- International Operations

- Marketing/Manufacturing Interfaces

- Multi-location inventory theory
- New Product \& Service Design

- Queuing Networks

- Reverse Logistics

- Service Logistics and Product Support

- Supply Chain Management

- Technology Management and Strategy

- Technology, Information and Operations in:

- Automotive Industries

- Electronics manufacturing

- Financial Services

- Health Care

- Media and Entertainment

- Process Industries

- Retailing

- Telecommunications

\section{Information for Librarians}

Foundations and Trends ${ }^{\circledR}$ in Technology, Information and Operations Management, 2017, Volume 11, 4 issues. ISSN paper version 1571-9545. ISSN online version 1571-9553. Also available as a combined paper and online subscription. 


\section{Contents}

Integrated Risk Management in Supply Chains: Overview and Future Directions

P. Kouvelis, L. Dong and D. Turcic

Part 1: Buffering Supply Chain Risk with Operational Flexibility 13

The Interaction between Operational Flexibility and Financial Flexibility

O. Boyabatli and T. Leng

Investments in Lead-Time Reduction: How to Finance and How to Implement

I. Biçer and R. W. Seifert

Part 2: Supply Disruption

Operational Hedging through Dual-Sourcing under Capacity Uncertainty

$X$. Chen 
Managing Supply Risk in Fixed Price Contracts: A Contingent Claims Perspective

B. Kamrad, R. Ji and G. M. Schmidt

Integrated Production Planning and Risk Hedging

L. Wang and D. D. Yao

Minimum-Variance Hedging for Managing Risks in Inventory Models with Price Fluctuations

C. Canyakmaz, F. Karaesmen, and S. Özekici

A Cournot-Stackelberg Model of Supply Contracts with Financial Hedging and Identical Retailers

R. Caldentey and M. Haugh

Approximations for High Dimensional Commodity and Energy Merchant Operations Models

N. Secomandi

Linking Commodity Price Risk and Operations: Evidence from the Gold Mining Industry

P. Markou and D. Corsten 


\section{Integrated Risk Management in Supply Chains: Overview and Future Directions}

The following volume, which surveys the most recent research in supply chain risk management, is motivated by the success of the third "Supply Chain Finance \& Risk Management Workshop," which was held at the Olin Business School of Washington University in St. Louis, on May 14-15, 2017. The workshop was organized in collaboration and with the financial support of the Boeing Center for Supply Chain Innovation (BCSCI) at Washington University. During the workshop, the participants wondered if it would be possible to establish an outlet that would give them a timelier access to the latest research on supply chain finance and supply chain risk management. (It is well-known, that due to review process lead times, articles that eventually make it into one of our top journals are typically 2 to 3 years old.) The idea of producing an edited volume, which would include an overview of the latest articles on the topics above appealed not only to the workshop participants but also to other active members of the iFORM (Interface of Finance, Operations, and Risk Management) research community. The Editor of "Foundations and Trends in Technology, Information and Operations Management", published by Now Publishers, Inc., Professor Charles Corbett was open to the idea and accepted our proposal to produce two volumes. The first volume is on the topic of supply chain finance and the second is on the subject of integrated risk management. 
The editors extended an invitation to 90 or so top researchers from the iFORM community who have participated in at least one of the supply chain finance and risk management workshops and who have seminal contributions in these areas. In response, the editors received 30 or so submissions. Following a careful review process, 21 manuscripts were eventually accepted for publication. The volume on supply chain finance includes 12 of the 21 papers, which are organized into four parts; the remaining papers, which are included in this volume, are organized in three parts.

\section{Overview of the Integrated Risk Management in Supply Chains Area}

In 2005, Pepsi Bottling Group (PBG) recognized that increased complexity in the bottling landscape and the competitive nature of the bottling industry required a new approach to production sourcing. Both the supply chain network and changing consumer preferences drove this complexity. PBG's North American network consists of 57 plants producing more than 1,200 stock keeping units distributed to 360 warehouses. Meanwhile, consumer preference shifted from cans to bottles, from carbonated soft drinks to non-carbonated drinks and toward shrink film packages. PBG produced these newly preferred products in limited locations. The end-result was that more than half of PBG's bottle lines operated at capacity and peak demand outstripped instantaneous production capacity. What did PBG do to address the problem? It focused on a flexible manufacturing strategy that matched production sourcing decisions with consumer preferences.

- Simchi-Levi (2010)

On March 17, 2000, lightning hit a power line in Albuquerque, New Mexico. The strike caused a massive surge in the surrounding electrical grid, which in turn started a fire at a local plant owned by Royal Philips Electronics, 
N.V., damaging millions of microchips. Scandinavian mobilephone manufacturer Nokia Corp., a major customer of the plant, almost immediately began switching its chip orders to other Philips plants, as well as to other Japanese and American suppliers. Thanks to its multiple-supplier strategy and responsiveness, Nokia's production suffered little during the crisis.

- Chopra and Sodhi (2004)

Intel Corporation incurs most of its expenses in the United States where it performs the bulk of its $R \& D$ and most of its manufacturing, but the company generates revenues throughout the world. Intel is subject to substantial currency risk because of the relatively long time between its quotation of a price to a customer and the customer's payment for the products. Intel's policy has been to actively hedge the currency exposures that arise in these situations.

- Hillier et al. (2008)

Corporations around the world devote substantial resources to risk management. The idea that corporations should manage exposure to various sources of risk is relatively new, but it is becoming increasingly important. Operations managers always applied various operational hedges in dealing with supply and demand risks (inventory and time buffers, excess capacity, operational flexibility, risk pooling, contingency plans, etc.), but they also learned that exchange rates and commodity risks might require combining financial hedges with operational hedges to counteract them. In contrast to the past, when the chief financial officer (CFO) of a corporation would spend a small portion of his time on hedging, many corporations now have entire departments devoted to risk management and hedging. Financial managers are in need to better understand how operational decisions create financial exposure to risks and that drives the nature of financial hedging instruments to be used.

To understand why corporations care about risk, we must first return to the Modigliani-Miller Theorem (Modigliani and Miller, 1958; Miller 
and Modigliani, 1961). The Modigliani-Miller Theorem was applied initially to the analysis of the firm's debt-equity choice. However, the theorem is much more general and can be applied to the analysis of all aspects of the firm's financial and risk management strategy. The assumptions of the theorem imply that investors, as well as corporations, can manage risk without incurring any transaction costs. Put it differently; the theorem hinges on equal access to hedging instruments. However, when it comes to supply chain risks (e.g., the risk of disruption) many individual investors do not have equal access. Therefore, one way to justify the study of corporate risk management is by challenging the equal access assumption.

In manufacturing, companies can hedge operationally and financially. Operational hedges, including inventory buffers and flexible production technologies, can be excellent protection against routine fluctuations in demand. Financial hedges, including trades in options and futures, can effectively protect manufacturers from routine fluctuations in prices of raw of materials and currency exchange rates. (Parts 1 and 3 of this volume are dedicated to the study of these strategies.)

Hedging with inventory or by trading in the financial markets, however, is less helpful as a protection against disasters. In 2011, Japan experienced an undersea megathrust earthquake off the Pacific coast of Tōhoku, which caused extensive damage to its manufacturing base. Throughout Japan, many plants were closed for days, with restart dates uncertain, causing ripple effects worldwide: for example, a General Motors truck plant in Louisiana was forced to halt production for lack of Japanese-made parts (Lohr, 2011).

Learning from the disaster, companies like GM and Toyota have ensured that multiple suppliers (and multiple suppliers of their suppliers) were able and ready to manufacture each component (Kubota, 2006). The supply chain literature refers to the automakers' approach as developing contingency scenarios, which is a technique that is normally used to deal with risks that are not frequent but consequential. (Part 2 of the volume is dedicated to managing supply disruptions.)

The trend toward greater attention to risk management is due to a number of factors, most notably, the increased volatility of commod- 
ity prices and exchange rates, recent natural disasters (e.g., hurricane Harvey, which caused widespread flooding in Houston and a spike in U.S. oil and gasoline prices), and the increased importance of multinational corporations. The motivation for risk management comes from a variety of sources: financial distress costs, managerial incentives, and other important reasons discussed in the remainder of this volume. Understanding the motives is important because they provide insights into which risks should be managed and how a firm's risk management operations should be organized.

\section{Part 1: Buffering Supply Chain Risk with Operational Flexibility}

The first part of the volume deals with uncertainty in the form of routine variability, which includes fluctuations in demand. The logical protection against the risk posed by routine variability is to install operational buffers either in the form of inventory or flexible production technology. To establish these buffers, however, firms require capital or a "monetary buffer." To maintain financial buffers, though, firms must be able to perform operationally, which in turn requires the aforementioned operational buffers. The interdependence of monetary and operational buffers is something that is explored in the first part of the volume.

In the first paper, "The Interaction between Operational Flexibility and Financial Flexibility," Onur Boyabatlı and Tiecheng Leng study the interaction between operational flexibility and financial flexibility in a multiproduct firm. A firm invested in flexible production technology capacity will be equipped with operational flexibility to handle uncertain demand across multiple products. The firm's capital availability for operations reflects its financial flexibility. They distinguish the firm's financial flexibility at the capacity investment stage from that at the production stage and investigate how the stringency of budget constraint at different stages affects the firm's optimal flexible-versus-dedicated technology choices. They show that operating budget can be interpreted as a flexible resource used in conjunction with the capacity investment, and as such it plays a vital role in technology choices. Whether flexible technology and financial flexibility are substitutes or complements 
depends on the severity of budget constraints at different stages and capacity intensity of technologies.

Reducing production lead-time improves a firm's market responsiveness. In the second paper, "Investments in Lead-Time Reduction: How to Finance and How to Implement," Işık Biçer and Ralf W. Seifert study the production lead-time reduction decision and its associated financing decision. They find that the payoff of lead-time reduction to equity holders is related to the profit margin of the product and the level of demand uncertainty. The study suggests that a firm should use equity-financing to finance lead-time reduction for products with high demand uncertainty and use debt financing for products with low demand uncertainty.

\section{Part 2: Supply Disruption}

Both the preponderance of natural disasters and huge economic swings can cause extreme challenges across the supply chains. Although these types of risks are rare, they are highly consequential and buffering (Part 1 ) is insufficient to mitigate them. Instead, firms facing these risks must engage in contingency planning and must maintain redundancies in the system (e.g., backup suppliers or backup labor force). But developing a contingency plan involves more than specifying resources. Firms must also decide which events warrant backup resources and to do this, firms must be able to determine the value that a contingency plan can create. The mechanics of such valuation are similar to valuing contingent claims in finance. This is why contingency planning is on the interface of operations and finance.

Dual/Multi sourcing is a common contingency strategy when supply sources are risky. In the first paper, "Operational Hedging through Dual-Sourcing under Capacity Uncertainty," Xin Chen summarizes his earlier works with coauthors on the optimal dual sourcing strategy when supply capacities are uncertain. In a finite planning horizon, a firm decides sourcing quantities from two suppliers with random capacities and positive replenishment lead times. The dynamic programming (DP) problem is a challenging one to solve because convexity property fails to hold for the objective function. He develops a transformation technique 
that converts the original nonconvex optimization to an equivalent convex optimization problem. The transformation also preserves structural properties such as convexity, submodularity, and L-convexity. The preservation of properties enables the proof of monotone comparative statics of the optimal solution. Using this technique, he shows that under certain conditions (on replenishment lead-time and supply capacity) a dual-index policy is the optimal dual sourcing policy. The monotonicity property of the optimal solution in state space can help further reduce computational effort.

The second paper is by Bardia Kamrad, Ran Ji, and Glen M. Schmidt on "Managing Supply Risk in Fixed Price Contracts: A Contingent Claims Perspective." The paper presents a general contingent claims model that can be adapted to model various risk-based operations problems. They adapt this model to the problem of valuing a fixed price contract contingent on supply yield uncertainty. Specifically, in a finite horizon setting, manufacturer sources from a portfolio of unreliable (subject to random yield) suppliers as well as from a reliable spot market (in case of supply shortage). In each period, in response to the realized yield uncertainty, the manufacturer optimally adjusts her portfolio weights (sourcing proportions) and her spot sourcing quantities. A numerical study generates interesting findings regarding the behavior of optimal portfolio weights along different types of lattice paths and in response to changes in spot prices, the value of the contract in response to supply portfolio volatility, and finds that the value of the flexibility of adjusting portfolio weights is always positive.

\section{Part 3: Commodity Price Risk}

Just about every manufacturing organization is exposed to commodity price risks. On the cost side, price volatility affects the direct costs of raw materials, components, subassemblies, and packaging materials purchased as well as indirect costs from the energy consumed in operations and transportation. For example, a food processing company may be exposed to price risk from commodities such as corn that is used in its products, from paper and plastics used in its packaging materials, and from diesel fuel for transportation in its distribution network. On 
the revenue side, the demand for discretionary purchase items is widely believed to be correlated with economic indicators, including equity and commodity market indexes. Both quantity and pricing decisions become more challenging when prices fluctuate; wrong decisions on managing these price risks can quickly cut into profit margins.

This volume includes five papers on managing price risks, which come in two distinct flavors. The first three papers are fundamental in the sense that they ask when and how firms should manage price risks with hedging and how hedging affects operating policy.

In the first paper titled "Integrated Production Planning and Risk Hedging," Liao Wang and David Yao study production planning integrated with risk hedging. Whereas traditional production planning models focus on the expected net-profit as an objective function, Liao Wang and David Yao study two risk measures, variance and shortfall. As such, their approach resembles the well-known Markowitz meanvariance portfolio optimization procedure. In both cases, the authors characterize and efficient "production" frontier and demonstrate an improved risk-return profile.

In a closely related paper titled "Minimum-Variance Hedging for Managing Risks in Inventory Models with Price Fluctuations," Caner Canyakmaz, Fikri Karaesmen and Süleyman Özekici identify a joint operating and hedging policy that minimizes the total variance of operational and financial returns.

Whereas the decision makers in the previous two papers are both standalone firms, in a paper "A Cournot-Stackelberg Model of Supply Contracts with Financial Hedging and Identical Retailers," René Caldentey and Martin Haugh consider a model where firms compete. Competition brings an interesting twist in the sense that hedging affects the intensity of competition and the resulting consumer welfare. Specifically, the authors find equilibria in which firms hedge although hedging causes competition to become more intense.

The remaining two papers can be seen as examining and reporting on best practices in specific industries. In the paper "Approximation for High Dimensional Commodity and Energy Merchant Operations Models," Nicola Secomandi presents a brief tutorial on the formulation 
and solution methods for merchant operations in commodity and energy industries. He gives a high-level discussion of four classes of heuristic approaches to the high-dimension Markov Decision Process (MDP) and efficiently explains the essence, strengths, and weaknesses of each approach. He also provides references to classic and recent works for readers interested in details of each method.

Finally, the last paper "Linking Commodity Price Risk and Operations," Panos Markou and Daniel Corsten empirically study risk management policies in the gold mining industry. Gold miners can manage risks financially, by committing to selling gold through forward contracts and call options, and operationally, by varying the grade of gold they process. Their data reveal that gold miners see the two methods as substitutes and that financial hedging has essential implications on gold inventory levels.

\section{Future Research}

In today's globalized economy, companies are gaining a competitive advantage by developing business relationships into more complex supply chains. While these relationships can produce gains in productivity and profitability, they often come at the price of taking on additional risk exposure. One can identify several areas as possible starting points for future research:

Risk mitigation through contracts. Topics such as supplier default risk, quality risk, and management of risk within a supply chain network have been understudied. Yet, they are prominent, especially in supply chains heavily influenced by prices of commodities (e.g., automotive supply chains).

Sustainability. While many risk management strategies (e.g., inventory buffers or capacity redundancy) can make sense on expected profit basis (something companies care about today) it can also be seen as wasteful. Sustainability (economic, environmental, and social) is likely to have a large influence on corporate decision making in not too distant future.

Risk management in service industries. Much of the existing literature focuses on risk mitigation in settings where firms manufacture 
goods. Risk management, however, can become a source of competitive advantage in service industries as well. For example, the backbone of a parcel delivery or ride-share company is still its drivers. But even veteran drivers with years on the same route can't compete with technology when it comes to finding the fastest, most fuel-efficient way to the final destination. That's why a company like UPS has invested heavily in a just launched new project, ORION, that it says will shorten drivers' routes and help overcome unexpected traffic delays. Rideshare services, including UBER, have been rumored to invest in similar software development efforts (Konrad, 2013).

Panos Kouvelis

Ling Dong Danko Turcic

Olin Business School Washington University in St. Louis 


\section{References}

Chopra, S. and M. S. Sodhi. 2004. "Managing Risk to Avoid SupplyChain Breakdown". MIT Sloan Management Review. Fall. URL: http : / / sloanreview . mit . edu / article / managing - risk - to - avoid supplychain-breakdown.

Hillier, D., M. Grinblatt, and S. Titman. 2008. Financial Markets and Corporate Strategy. European edition. McGraw-Hill Education.

Konrad, A. 2013. "Meet ORION, Software That Will Save UPS Millions by Improving Drivers' Routes". URL: https://www.forbes.com/sites/ alexkonrad/2013/11/01/meet-orion-software-that-will-save- upsmillions-by-improving-drivers-routes/\#6b9d47b84fc7.

Kubota, Y. 2006. "Japan Earthquakes Rattle Toyota's Vulnerable Supply Chain". The Wall Street Journal. 19 Apr. 2006. URL: https: //www.wsj.com/articles/japan-earthquakes-rattle-toyotas-supplychain-1460986805.

Lohr, S. 2011. "Stress Test for the Global Supply Chain". The New York Times. 19 Mar. 2011. URL: http://www.nytimes.com/2011/03/ 20/business/20supply.html?pagewanted=all.

Miller, M. and F. Modigliani. 1961. "Dividend Policy, Growth, and Valuation of Shares". The Journal of Business. 34(4): 411-433.

Modigliani, F. and M. Miller. 1958. "The Cost of Capital, Corporation Finance and the Theory of Investment". American Economic Review. 48(3): 261-197. 
Simchi-Levi, D. 2010. Operations Rules: Delivering Customer Value through Flexible Operations. The MIT Press. 